\title{
PATIENT SELECTION CRITERIA FOR LUNG VOLUME REDUCTION SURGERY
}

Robert J. McKenna, Jr., MD, FACS

Matthew Brenner, MD

Richard J. Fischel, MD, PhD

Narinder Singh, MD

Ben Yoong, MD

Arthur F. Gelb, MD

Kathryn E. Osann, PhD
Objective: Our intent was to refine the patient selection criteria for lung volume reduction surgery because various centers have different criteria and not all patients benefit from the procedure. Methods: Patient information, x-ray results, arterial blood gases, and plethysmographic pulmonary function tests in 154 consecutive patients who underwent bilateral thoracoscopic staple lung volume reduction surgery were compared with clinical outcome (change in forced expiratory volume in 1 second and dyspnea scale) with $t$ tests and analysis of variance. Results: Three hundred thirty-three of 487 (69\%) patients evaluated for lung volume reduction surgery were rejected for lack of heterogeneous emphysema $(n=212)$, medical contraindications $(n=88)$, hypercapnia $(n=20)$, uncontrolled anxiety or depression $(n=10)$, or pulmonary hypertension $(n=1)$. Two patients died during the evaluation process. When tested by analysis of variance, there was no difference in clinical outcome associated with preoperative forced expiratory volume in 1 second, residual volume, total lung capacity, single-breath diffusing, and arterial oxygen or carbon dioxide tension. All patients selected for the operation had a heterogeneous pattern of emphysema. The upper lobe heterogeneous pattern of emphysema on chest computed tomography and lung perfusion scan was strongly associated with improved outcome with a mean (95\% confidence interval) improvement in forced expiratory volume in 1 second of $73.2 \%$ (63.3 to 83.1) for the upper lobe compared with a mean (95\% confidence interval) improvement of $37.9 \%$ (22.9 to 53.0) for the lower lobe or diffuse pattern of emphysema. Conclusion: The most important selection criteria for lung volume reduction surgery is the presence of a bilateral upper lobe heterogeneous pattern of emphysema on chest computed tomography and lung perfusion scan. After patients have been selected on the basis of a heterogeneous pattern of emphysema, clinical factors and physiology are not associated with clinical outcome well enough to further refine patient selection criteria. These results do not support the arbitrary patient selection criteria for lung volume reduction surgery reported in the literature. (J Thorac Cardiovasc Surg 1997;114:957-67)
W hen Cooper and associates ${ }^{1}$ reported an $82 \%$ improvement in forced expiratory volume in 1 second $\left(\mathrm{FEV}_{1}\right)$ after lung volume reduction surgery

From the Lung Center, Chapman Medical Center (R.J.M., R.J.F., N.S.), Orange, Calif., the Pulmonary Department (A.F.G.), Lakewood Regional Medical Center, Lakewood, Calif., and the Pulmonary Division, UCI Medical Center (M.B.), Beckman Laser Institute (M.B., B.Y.), UCLA Pulmonary Division (A.F.G.), and UCLA Thoracic Surgery (R.J.M., R.J.F.), Los Angeles, Calif.

Supported in part by DOE grant DE-f603-91 ER61227, National Institutes of Health grant R01192, and the Heart and Lung Surgery Foundation.
(LVRS), they created tremendous interest in this procedure, because no previous treatment (aside from lung transplantation) had been shown to im-

Read at the Twenty-first Annual Meeting of The Western Thoracic Surgical Association, Coeur d'Alene, Idaho, June 21-24, 1995.

Received for publication July 3, 1996; revisions requested Feb. 13, 1997; revisions received June 16, 1997; accepted for publication July 31, 1997.

Address for reprints: Robert J. McKenna, Jr., MD, 8635 Third, Suite 975W, Los Angeles, CA 90048.

Copyright (c) 1997 by Mosby-Year Book, Inc.

$0022-5223 / 97 \$ 5.00+0 \quad \mathbf{1 2 / 6 / 8 5 2 7 8}$ 
prove pulmonary function for persons who were severely disabled by emphysema. Results from other authors have confirmed that LVRS produces significant improvement in pulmonary function, freedom from supplementary oxygen, and quality of life. ${ }^{1-10}$

There were many questions regarding the optimal surgical technique, mechanisms of improvement; and patient selection for LVRS when Cooper's group $^{1}$ reported on their first 20 patients. In a randomized prospective study, $\mathrm{we}^{9}$ showed that the staple technique produced a greater improvement in $\mathrm{FEV}_{1}(33 \%$ vs $13 \%)$ and quality of life than the laser technique. Bilateral staple LVRS resulted in greater freedom from supplementary oxygen ( $68 \%$ vs $35 \%$ ), prednisone independence ( $86 \%$ vs $56 \%$ ), and improvement in pulmonary function $(57 \%$ vs $35 \%)$ than unilateral staple LVRS. ${ }^{10}$ The mechanism of improvement is a significant improvement in lung elastic recoil and compliance without any change in chest wall compliance.

The reported series of LVRS have recommended specific patient selection criteria regarding age, hypercarbia, prednisone use, oxygen use, diaphragmatic excursion, plethysmographic results, and the radiologic pattern of emphysema. In these series, there is considerable variation in patient selection criteria and little or no objective data to support the establishment of these criteria. Recent editorials call for better definition of patient selection. ${ }^{11,12}$

All patients in this series have a heterogeneous pattern of emphysema. Our follow-up has shown that the condition of a high percentage of our patients is significantly improved, but that a minority of patients have only mild improvement and some have no improvement at all. This review was therefore undertaken to specifically analyze our results after bilateral staple LVRS to further refine the selection criteria when LVRS is performed for patients with a heterogeneous pattern of emphysema.

\section{Patients and methods}

Between May 1995 and May 1996, 154 patients underwent bilateral staple LVRS at Chapman Medical Center with a previously described video-assisted thoracic surgery technique. ${ }^{9}, 10$ This included 98 men and 56 women with a mean age of $67.1 \pm 6.8$ years (range 45 to 79 years).

These cases were analyzed to evaluate the potential selection criteria for LVRS. Routine preoperative evaluation included history and physical examination, arterial blood gases with the patient breathing room air, chest roentgenogram, chest computed tomographic (CT) scan, lung perfusion scan, and pulmonary function tests by helium dilution and plethysmography.

Entry criteria for selection in this series have been previously described. , $^{10}$ Despite maximal medical management, all patients had marked symptoms, as measured by dyspnea index ${ }^{13}$ and quality of life assessment. ${ }^{14}$ Chest roentgenograms showed hyperexpansion of the thorax with flattening or inversion of the diaphragm.

Contraindications to surgery included current cigarette smoking, age older than 80 years, severe cardiac disease, history of cancer within the past 5 years, ventilator dependency, or prior thoracic surgery. Relative contraindications included age older than 75 years, seyere anxiety, severe depression, or severe carbon dioxide retention (arterial carbon dioxide tension $\left[\mathrm{PaCO}_{2}\right]>55 \mathrm{~mm} \mathrm{Hg}$ ).

To be accepted for the procedure, patients had to have a pattern of emphysema on CT that was heterogeneous and graded as severe. ${ }^{15}$ The $C T$ scan pattern was clasșified as upper lobe if the emphysema was primarily in the upper lobes, lower lobe if concentrated in the lower lobes, and diffuse if there was a heterogeneous pattern of emphysema with discrete areas of severe emphysema present in both upper and lower lobes. Radionuclide lung perfusion scans were also used to confirm the heterogeneous pattern of emphysema.

All patients underwent room air arterial blood gas analysis and lung function studies that included static lung volumes measured by plethysmographic techniques, ${ }^{16}$ timed spirometry and single-breath diffusing capacity (DLCO) in accordance with American Thoracic Society recommendations, ${ }^{17,18}$ and values were compared with predictions. ${ }^{19-21}$ All patients were considered to have fixed airflow limitation since the $\mathrm{FEV}_{1}$ after three inhalations of aerosolized albuterol (INN: salbutamol) $(670 \mu \mathrm{g}) \mathrm{im}-$ proved less than $12 \%$ and/or less than $200 \mathrm{ml}^{18}$ The best post-bronchodilator $\mathrm{FEV}_{1}$ was used for preoperative and postoperative evaluation of the patients. Maximum inspiratory and expiratory flow volume curves, thoracic gas volume, ${ }^{16}$ and airway resistance ${ }^{16}$ were measured in a plethysmograph (models 2800 and 6200, Sensormedics, Inc., Yorba Buena, Calif.) and compared with predicted values. ${ }^{22}$ The reciprocal of airway resistance, ${ }^{16}$ conductance, was divided by the thoracic gas volume at which it was measured to calculate specific conductance. Residual volume was calculated by subtracting vital capacity from total lung capacity. Complete lung function studies were obtained before the operation. Generally, only timed spirometry and arterial blood gases were available after the operation.

All patients were clinically assessed and followed up with the Medical Outcome Survey (MOS) 36-item shortform health survey ${ }^{23}$ and the Modified Medical Research Council (MMRC) dyspnea scale. ${ }^{24}$ Preoperative arterial blood gases for the patients who underwent the operation showed a mean (95\% confidence interval $[\mathrm{CI}]$ ) arterial oxygen tension $\left(\mathrm{PaO}_{2}\right)$ of $65.41 \mathrm{~mm} \mathrm{Hg}(63.26$ to $67.56 \mathrm{~mm}$ $\mathrm{Hg})$ and an arterial carbon dioxide tension $\left(\mathrm{PaCO}_{2}\right)$ of $42.90 \mathrm{~mm} \mathrm{Hg}(41.70$ to $44.10 \mathrm{~mm} \mathrm{Hg}$ ). Preoperative pulmonary function tests showed a mean $(95 \% \mathrm{CI}) \mathrm{FEV}_{1}$ of $0.64 \mathrm{~L}(0.61$ to $0.69 \mathrm{~L})$, a forced vital capacity of $2.01 \mathrm{~L}$ (1.89 to $2.13 \mathrm{~L})$, a total lung capacity of $7.18 \mathrm{~L}$ (6.88 to 7.48 $\mathrm{L})$, a residual volume of $4.52 \mathrm{~L}(4.28$ to $4.76 \mathrm{~L})$, and a residual volume/total lung capacity of $0.66(0.65$ to 0.68$)$.

Most patients had undergone pulmonary rehabilitation, but it was not a preoperative requirement. 
Table I. Relationship between radiologic pattern of emphysema and clinical outcomes

\begin{tabular}{|c|c|c|c|c|}
\hline & $\Delta F E V_{I}(L)$ & $\% \triangle F E V_{7}$ & $\Delta \%$ Pred & sDyspnea \\
\hline Pattern & Mean $(95 \%$ CI) & Mean $(95 \%$ CI) & Mean $(95 \% \mathrm{CI})$ & Mean $(95 \% C I)$ \\
\hline Upper lobe & $0.43(0.37,0.49)$ & $73.18(63.29,83.06)$ & $16.72(14.60,18.84)$ & $1.63(1.40,1.86)$ \\
\hline Low/diffuse & $0.22(0.15,0.30)$ & $37.95(22.92,52.97)$ & $8.43(5.15,11.70)$ & $1.88(1.40,2.36)$ \\
\hline Significance* & $p=0.0013$ & $p=0.0007$ & $p=0.0002$ & $p=0.34$ \\
\hline
\end{tabular}

Pattem, Location of the areas of emphysema targeted for resection; Low/diffusion, patients with areas of emphysema in lower lobes or multiple lobes for resection; $\triangle F E V_{1}$, change from baseline $F E V_{1}$ in liters; $\% \triangle F E V_{l}$, percent change from baseline $F E V_{1}$ in liters; $\triangle \%$ Pred, change from baseline percent predicted $\mathrm{FEV}_{1} ; \Delta D y$ spnea, change in dyspnea score.

${ }^{*} t$ Test for difference between two means.

Clinical follow-up was available for all patients. There were seven deaths among the 154 patients (4.5\%). Follow-up pulmonary function tests were available for 138 of 147 (93.9\%) surviving patients. The mean (95\% CI) length of stay for all patients was 9.3 days (8.3 to 10.3 days) and for patients with follow-up data it was 8.8 days ( 7.8 to 9.8 days, range 3 to 36 days).

Statistical analysis. Associations between preoperative patient characteristics and clinical outcome were investigated with the use of $t$ tests (for comparisons between two groups) and analysis of variance (ANOVA) (comparison of more than two groups). The measures of clinical outcome used in the analyses include change in $\mathrm{FEV}_{1}$, percent change from baseline $\mathrm{FEV}_{1}$, change in $F E V_{1}$ percent predicted, and change in dyspnea score. Independent or grouping variables included patient characteristics previously described as selection criteria in published series of LVRS. Two-way ANOVA was used to investigate the independent effects of two independent variables and possible interactions between them. Analyses were conducted with the use of the BMDP statistical software package (BMDP Software, Los Angeles, Calif.).

Cut points for continuous independent variables used in ANOVA models were chosen on the basis of biologic plausibility and prior research. Age was analyzed in 5-year groups ( 60 to 64,65 to 69,70 to 74 , and $75+$ years) to investigate the possibility of a nonlinear relationship between age and clinical outcome. Pairwise differences between groups were examined with the use of $t$ tests with a Bonferroni adjustment for multiple comparisons. Because the extreme age subgroups (youngest and oldest age groupings) included smaller numbers and did not differ significantly from adjacent subgroups, they were combined to form two age groups $(<70$ and $70+$ years) for the ANOVA models presented.

\section{Results}

During the time period of this series, 333 of 487 (69\%) patients evaluated for LVRS were turned down for the following reasons: lack of heterogeneous pattern of emphysema $(n=212)$, medical contraindications $(n=88)$, hypercapnia $(n=20)$, uncontrolled anxiety or depression $(n=10)$, or pulmonary hypertension $(n=1)$; two patients died while awaiting the operation. The percent of patients chosen for LVRS was as high as $31 \%$ because some pulmonologists who regularly refer patients to this center prescreen their patients so that almost all of the patients that they refer meet our criteria for the procedure. Clinical follow-up data are available for all patients and pulmonary function data are available for 138 of 147 surviving patients.

Roentgenographic pattern of emphysema. Clinical response to the operation was compared with the roentgenographic pattern of emphysema. The location of the emphysema targeted for resection was upper lobe in $106(77 \%)$, lower lobe in $10(7 \%)$, and diffuse in $22(16 \%)$ of the patients. Clinical outcome, measured by all three variables assessing change in $\mathrm{FEV}_{1}$, was significantly better for upper lobe pattern than for other patterns ( $t$ test for difference between means, $p<0.001$ for each outcome variable). Patients with upper lobe disease experienced a $73.2 \%$ improvement in $\mathrm{FEV}_{1}$ from a preoperative mean of 0.64 (95\% CI, 0.59 to 0.70$)$ to a postoperative mean of 1.07 (95\% CI, 0.98 to 1.16 ). By comparison, patients with diffuse or lower lobe disease experienced a $38 \%$ improvement in $\mathrm{FEV}_{1}$ (preoperative mean $=0.70[95 \% \mathrm{CI}, 0.63$ to 0.78$]$; postoperative mean $=0.93[95 \% \mathrm{CI}, 0.85$ to 1.01$]$ ) . In contrast, however, there was no significant difference in the change in dyspnea scale for the three patterns $(p=0.34)$ (Table I).

Age. To investigate the association between age and clinical outcome, we compared change in $\mathrm{FEV}_{1}$ among age-specific groups using one-way ANOVA. Patients aged 70 years or older experienced significantly less improvement than did patients younger than 70 for all measures of change in FEV (Table II). Patients aged 70 years or older experienced a $48 \%$ improvement in the $\mathrm{FEV}_{1}$ (preoperative $\mathrm{FEV}_{1}$ mean of $0.69 \mathrm{~L}$ [95\% CI, 0.61 to $0.76 \mathrm{~L}$ ] and postoperative $\mathrm{FEV}_{1}$ mean of $0.97 \mathrm{~L}[95 \% \mathrm{CI}, 0.87$ to $1.06 \mathrm{Ll})$ compared with an increase of $76 \%$ in younger patients (from a preoperative $\mathrm{FEV}_{1}$ mean of 0.64 [95\% Cl, 0.58 to 0.70$]$ to a postoperative mean of 1.08 [ $95 \%$ CI, 0.98 to 1.18]). Although older 
Table II. Relationship between age and clinical outcomes

\begin{tabular}{|c|c|c|c|c|}
\hline & $\Delta F E V_{1}(L)$ & $\% \triangle F E V_{1}$ & $\Delta \%$ Pred & DDyspnea \\
\hline Age & Mean $(95 \%$ CI $)$ & Mean $(95 \% \mathrm{CI})$ & Mean $(95 \%$ CI) & Mean $(95 \% \mathrm{CI})$ \\
\hline$<70 \mathrm{yr}$ & $0.44(0.36,0.52)$ & $76.16(63.55,88.76)$ & $16.65(14.00,19.30)$ & $1.84(1.57,6.27)$ \\
\hline$\geq 70 \mathrm{yr}$ & $0.28(0.23,0.34)$ & $47.64(38.96,56.33)$ & $11.92(9.58,14.27)$ & $1.47(1.15,1.78)$ \\
\hline Significance* & $p=0.014$ & $p=0.0004$ & $p=0.01$ & $p=0.08$ \\
\hline
\end{tabular}

$\triangle F E V_{1}$, Change from baseline $\mathrm{FEV}_{1}$ in liters; $\% \Delta F E V_{1}$, percent change from baseline $\mathrm{FEV}_{1}$ in liters; $\triangle \%$ Pred, change from baseline percent predicted $\mathrm{FEV}$; $\triangle D y s p n e a$, change in dyspnea score.

${ }^{*} t$ Test for difference between two means.

patients experienced a smaller change in the mean dyspnea score, 1.47 (95\% CI, 1.15 to 1.78 ) in older patients compared with 1.84 (95\% CI, 1.57 to 6.27 ) for younger patients), the difference was not statistically significant $(p=0.08)$.

When the effects of the emphysema pattern and age were examined simultaneously in a two-way ANOVA model, the effect of emphysema pattern retained statistical significance for all end points. A significant independent age effect was observed only for the comparison with $\mathrm{FEV}_{1}$ percent change from baseline used as the outcome. For other outcome variables, there was no longer a significant difference in clinical outcome between older and younger patients after adjusting for roentgenographic emphysema pattern (Table III).

There were no deaths among the 16 patients 75 years of age or older (range 75 to 81 years) who underwent LVRS. They experienced a $54 \%$ improvement in the $\mathrm{FEV}_{1}$ from a preoperative mean $\mathrm{FEV}_{1}$ of $0.63 \mathrm{~L}$ to a mean postoperative $\mathrm{FEV}_{1}$ of 0.97 L. Three $(18.75 \%)$ patients experienced no improvement in their dyspnea, and one (6.25\%) patient improved one dyspnea grade. The other nine patients $(56 \%)$ showed very substantial clinical improvement with at least a two-grade improvement in dyspnea scale. The mean improvement in the dyspnea score was $1.36 \pm 1.28$ for patients 75 years of age or older.

Prednisone use. There were no significant differences in $\mathrm{FEV}_{1}$ change associated with preoperative prednisone dose (see the appendix). Although ANOVA showed a significant difference in dyspnea change associated with different doses of prednisone, there was no significant trend in dyspnea change with increasing dose.

Dyspnea change was greatest for patients whose preoperative prednisone dose was 6 to $10 \mathrm{mg}$ and lowest for patients with a preoperative dose greater than $10 \mathrm{mg}$. Patients receiving more than $10 \mathrm{mg}$ of prednisone before the operation included three at a dose of $15 \mathrm{mg}$, one receiving $17.5 \mathrm{mg}$, eight receiving $20 \mathrm{mg}$, and one patient receiving a preoperative dose of $40 \mathrm{mg}$. Their $\mathrm{FEV}_{1}$ increased $62 \%$ from a preoperative mean of $0.66(95 \% \mathrm{CI}, 0.49$ to 0.83$)$ to a postoperative mean of 1.00 (95\% CI, 0.75 to 1.25$)$. By comparison, patients whose preoperative prednisone dose was $10 \mathrm{mg}$ or less experienced an increase in $\mathrm{FEV}_{1}$ of $66 \%$ (preoperative mean of 0.66 [95\% CI, 0.61 to 0.71]; postoperative mean of 1.05 [95\% CI, 0.97 to 1.13$]$ ]). Dyspnea grade decreased by 1.06 (95\% CI, 0.27 to 1.86 ) for patients receiving more than $10 \mathrm{mg}$ of prednisone compared with a decrease in grade of $1.72(95 \% \mathrm{CI}, 1.48$ to 1.97$)$ in patients receiving $10 \mathrm{mg}$ or less.

For patients receiving at least $20 \mathrm{mg}$ of prednisone per day, the length of stay averaged $10.4 \pm$ 1.7 days, compared with the 9.4 day mean length of stay for the entire series.

Severe hypoxemia. ANOVA models showed no association between preoperative room air blood gas $\mathrm{PaO}_{2}$ and postoperative change in $\mathrm{FEV}_{1}$ or dyspnea score (see the appendix).

Preoperatively, 18 patients had a mean room air blood gas $\mathrm{PaO}_{2}$ of less than $50 \mathrm{~mm} \mathrm{Hg}$, that is, 46.00 $\mathrm{mm} \mathrm{Hg}(95 \% \mathrm{CI}, 44.52$ to $47.48 \mathrm{~mm} \mathrm{Hg}$ ), range 40 to $50 \mathrm{~mm} \mathrm{Hg}$. For these patients, mean $\mathrm{PaO}_{2}$ levels increased $16.1 \mathrm{~mm} \mathrm{Hg}$ after the operation to 62.1 $\mathrm{mm} \mathrm{Hg}$ (95\% CI, 53.22 to $70.96 \mathrm{~mm} \mathrm{Hg}$ ). Preoperative mean $\mathrm{FEV}_{1}$ increased by $91 \%$ from a baseline of 0.61 (95\% CI, 0.43 to 0.79$)$ to a postoperative mean of 1.16 (95\% CI, 0.82 to 1.51$)$. Three (16.7\%) of these patients experienced no increase in $\mathrm{FEV}_{1}$.

In the overall series, $68 \%$ of patients receiving oxygen before the operation were weaned from oxygen supplementation completely after the procedure. In contrast, only four (22\%) of the 18 patients with preoperative $\mathrm{PaO}_{2}$ less than $50 \mathrm{~mm} \mathrm{Hg}$ were successfully weaned from supplementary oxygen.

Supplemental oxygen use. The results for all subsets of patients using less than $4 \mathrm{~L}$ of supplemental oxygen before the operation were indistinguishable 
Table III. Relationship between age and x-ray pattern of emphysema with clinical outcomes

\begin{tabular}{|c|c|c|c|c|c|}
\hline & & $\Delta F E V_{1}(L)$ & $\% \triangle F E V_{1}$ & $\Delta \%$ Pred & ADyspnea \\
\hline Age & Pattern & Mean $(95 \% \mathrm{CI})$ & Mean $(95 \% \mathrm{CI})$ & Mean $(95 \% \mathrm{CI})$ & Mean $(95 \%$ CI) \\
\hline$<70 \mathrm{yr}$ & Upper & $0.50(0.41,0.59)$ & $85.75(71.75,99.75)$ & $18.90(15.93,21.86)$ & $1.79(1.50,2.09)$ \\
\hline$<70 \mathrm{yr}$ & Low/diff & $0.24(0.13,0.35)$ & $42.30(19.66,64.93)$ & $8.73(4.56,12.89)$ & $2.04(1.40,2.68)$ \\
\hline$\geq 70 \mathrm{yr}$ & Upper & $0.31(0.25,(0.37)$ & $52.79(43.25,62.32)$ & $13.19(10.73,15.65)$ & $1.42(1.06,1.77)$ \\
\hline$\geq 70 \mathrm{yr}$ & Low/diff & $0.20(0.07,0.33)$ & $31.79(14.17,49.41)$ & $8.00(2.52,13.49)$ & $1.67(0.94,2.40)$ \\
\hline
\end{tabular}

Age, Greater or less than 70 years; Pattern, location of the areas of emphysema targeted for resection; Upper, upper lobe areas of emphysema targeted for resection; Low/diff, lower or diffuse areas of emphysema targeted for resection; $\triangle F E V_{1}$, change from baseline $\mathrm{FEV}_{1}$ in liters; \% $\triangle F E V_{l}$, percent change from baseline $\mathrm{FEV}_{1}$ in liters; $\triangle \%$ Pred, change from baseline percent predicted $F E V_{1} ; \Delta D y s p n e a$, change in dyspnea score.

from each other, but the outcomes were significantly worse for patients using $4 \mathrm{~L}$ of supplemental oxygen before the operation.

Preoperatively, eight patients required $4 \mathrm{~L}$ of continuous supplemental nasal oxygen. Despite a $60 \%$ increase in the $\mathrm{FEV}_{1}$ from the mean preoperative level of $0.55 \mathrm{~L}$ to the postoperative level of $0.89 \mathrm{~L}$ for these eight patients, four $(50 \%) \mathrm{pa}-$ tients had no change in their dyspnea scale and four $(50 \%)$ improved one grade. For patients using less than $4 \mathrm{~L}$ of supplemental oxygen in the perioperative period, the mean improvement in the dyspnea scale was 1.68 , compared with only 0.5 for patients using $4 \mathrm{~L}$ of supplemental oxygen. All patients requiring $4 \mathrm{~L}$ of supplemental oxygen before the operation continued to use supplemental oxygen after the operation, compared with a $68 \%$ chance of oxygen independence for all patients in the series who required oxygen supplementation in the preoperative period.

Hypercarbia. There was no association between room air $\mathrm{PaCO}_{2}$ and any of the outcome variables measured as changes in $\mathrm{FEV}_{1}$ or dyspnea score (see the appendix).

Preoperatively, 10 patients had a room air blood gas that showed levels of $\mathrm{PaCO}_{2}$ greater than $55 \mathrm{~mm}$ $\mathrm{Hg}$ (mean of 58.8 [95\% CI, 56.3 to 61.3]). The postoperative room air blood gas showed a mean $\mathrm{PaCO}_{2}$ of $42.1 \mathrm{~mm} \mathrm{Hg}$.

Their preoperative mean $\mathrm{FEV}_{1}$ increased by $71 \%$ after LVRS from $0.48 \mathrm{~L}(95 \% \mathrm{CI}, 0.38$ to 0.58$)$ to a postoperative mean of $0.81 \mathrm{~L}$ (95\% CI, 0.55 to 1.07 ), compared with a $62 \%$ change in patients with preoperative $\mathrm{PaCO}_{2}$ less than $55 \mathrm{~mm} \mathrm{Hg}$ from preoperative mean $\mathrm{FEV}_{1}$ of $0.67 \mathrm{~L}$ (95 $5 \mathrm{CI}, 0.62$ to $0.71 \mathrm{~L}$ ) to a postoperative mean $\mathrm{FEV}_{1}$ of $1.04 \mathrm{~L}(95 \% \mathrm{CI}$, 0.97 to $1.12 \mathrm{~L}$ ). In patients with preoperative $\mathrm{PaCO}_{2}$ greater than $55 \mathrm{~mm} \mathrm{Hg}$, dyspnea score decreased by a mean of 1.4 ( $95 \% \mathrm{CI}, 0.64$ to 2.11) compared with a decrease of 1.7 (95\% CI, 1.48 to 1.92) in patients with a lower preoperative $\mathrm{PaCO}_{2}$.
Diaphragmatic excursion. Twenty-two patients had diaphragmatic excursion greater than $3 \mathrm{~cm}$ on at least one side. The average improvement in $\mathrm{FEV}_{1}$ for this group of patients was $0.37 \mathrm{~L}(95 \% \mathrm{CI}, 0.28$ to $0.46 \mathrm{~L})$ compared with $0.38 \mathrm{~L}(95 \% \mathrm{CI}, 0.32$ to $0.44 \mathrm{~L}$ ) for patients with diaphragmatic excursion less than or equal to $3 \mathrm{~cm}$ ( $t$ test for difference between groups, $p=0.21$ ).

Pulmonary function test criteria. There was no difference in outcome measured as change in $\mathrm{FEV}_{1}$ $(F=0.71, p=0.49)$, change in $\mathrm{FEV}_{1}$ percent predicted $(F=0.36, p=0.70)$, or change in dyspnea score $(F=0.05, p=0.95)$, when they were compared by preoperative level of $\mathrm{FEV}_{1}$ by means of one-way ANOVA (see the appendix).

For 55 patients with a preoperative $\mathrm{FEV}_{1}$ less than $0.5 \mathrm{~L}$, the mean length of stay in the hospital was 11.1 days and there were five deaths (9\%). This subgroup of patients experienced an $87 \%$ improvement in $\mathrm{FEV}_{1}$, preoperative mean of $0.39(95 \% \mathrm{CI}$, 0.37 to 0.41 ) to a postoperative mean $\mathrm{FEV}_{1}$ of 0.73 (95\% CI, 0.67 to 0.78 ), compared with $56 \%$ improvement from baseline in patients with $\mathrm{FEV}_{1}$ greater than $0.5 \mathrm{~L}$, preoperative mean of $0.76(95 \%$ CI, 0.71 to 0.81 ) to a postoperative mean of 1.16 ( $95 \% \mathrm{CI}, 1.07$ to 1.24 ). The dyspnea score decreased by $1.71(95 \% \mathrm{CI}, 1.36$ to 2.05$)$ for patients with $\mathrm{FEV}_{1}$ less than $0.5 \mathrm{~L}$ compared with $1.67(95 \% \mathrm{CI}$, 1.41 to 1.93 ) for patients with an $\mathrm{FEV}_{1}$ greater than $0.5 \mathrm{~L}(p=0.63)$.

Appendix Fig. 1 shows the scattergrams comparing the preoperative plethysmographic criteria with the postoperative change in $\mathrm{FEV}_{1}$. Appendix Table I shows the lack of association between the plethysmographic criteria and the percent change from baseline $\mathrm{FEV}_{1}$ after bilateral staple LVRS.

\section{Discussion}

Early reports of LVRS suggest that the optimal operation is a bilateral staple operation that improves the $\mathrm{FEV}_{1}$ between $55 \%$ and $98 \% .^{1-9} \mathrm{Al}-$ 
Table IV. Summary of selection criteria by history for LVRS at multiple centers (listed by reference number)

\begin{tabular}{|c|c|c|c|c|c|c|c|c|}
\hline & \multicolumn{8}{|c|}{ Reference number } \\
\hline & 1,2 & 3 & 4 & 5 & 6,7 & 8 & 9,10 & 25 \\
\hline Age & $<75$ & $<85$ & $<70$ & $>75$ & No & $<75$ & $<80$ & - \\
\hline Amb. & Yes & No & Yes & Yes & Yes & Yes & Yes & - \\
\hline Vent & Yes & - & Yes & Yes & Yes & Yes & Yes & Yes \\
\hline Pred & $<10$ & - & $<15$ & $<20$ & $<20$ & High dose & $<20$ & - \\
\hline $\mathrm{O}_{2}$ & $<6 \mathrm{~L}$ & - & $<6 \mathrm{~L}$ & - & - & - & - & - \\
\hline Smoke free & $6 \mathrm{mo}$ & $6 \mathrm{mo}$ & $1 \mathrm{yr}$ & $6 \mathrm{mo}$ & $6 \mathrm{mo}$ & $6 \mathrm{mo}$ & $6 \mathrm{mo}$ & - \\
\hline Rehab & Yes & No & Yes & Yes & No & Yes & No & Yes \\
\hline PAS & $<45$ & - & $<45$ & - & - & - & - & - \\
\hline PAM & $<35$ & - & $<35$ & - & - & $<35$ & - & - \\
\hline
\end{tabular}

$A m b$, Requirement for a patient to be ambulatory; Vent, patient supported by a ventilator; $O_{3}$, preoperative oxygen requirement; Smoke free, requirement for smoke-free status; Rehab, successful completion of a rehabilitation with a requirement for 30 minutes on a treadmill; $P A S$, pulmonary artery systolic pressure; $P A M$, pulmonary artery mean pressure.

though there are as many as 2 million Americans who have emphysema, some of these persons are not candidates for LVRS. A key issue for LVRS is the proper selection of patients.

The most important concept of patient selection for LVRS is to identify patients with hyperexpanded lungs with areas of lung tissue that have little to no pulmonary function. The basic concept of the operation is to resect these nonfunctional areas to allow improved function by the remaining areas with less emphysematous change. Therefore the first and foremost selection factor has been the presence of a heterogeneous pattern of emphysema. In this series, the lack of this pattern was the most common contraindication for the operation. This review was undertaken in an effort to further refine the selection criteria for LVRS in patients with a heterogeneous pattern of emphysema.

Tables IV and $\mathrm{V}$ show the various selection criteria reported by eight different centers. ${ }^{1-10,25}$ Because there is little information in these papers to support these selection criteria, we reviewed our series to evaluate the validity of these patient selection criteria.

A reasonable justification for patient selection is a life expectancy long enough to justify the procedure. All centers except one noted that patients were excluded if they had significant coronary artery disease, any severe medical illness, or cancer other than prostate cancer.

There was general agreement that there should be an upper limit to age, although the limit varied from 70 to 85 years. ${ }^{3,4}$ In the present series, there were no deaths in 17 patients over 75 years of age. Clinically, both $\mathrm{FEV}_{1}$ and the dyspnea scale improved significantly. Therefore no absolute upper age limit could be identified from our data. Patients over 70 years of age showed significant clinical improvement, although this was not as large an improvement as that achieved by patients less than 70 years of age $(p=0.0004)$.

Patients requiring $4 \mathrm{~L}$ of oxygen before the operation showed little or no relief of dyspnea and no oxygen independence; thus this does appear to be a very strong contraindication to LVRS.

Six centers included a psychologic assessment as part of the preoperative evaluation. Miller, Lee, and Mansour ${ }^{4}$ stated that "panic attacks postoperatively were the most significant factor leading to postoperative complications and poor outcome." Because this has also been our clinical impression, all members of our team, including the physicians, nurses, the rehabilitation team, and respiratory therapists, assess potential candidates for severe anxiety or depression. In an attempt to identify anxiety and depression, patients are now routinely tested with the Beck anxiety and depression indices. Our pilot study suggests that these tools do identify patients at risk for a poor postoperative course.

Pulmonary artery pressures are criteria for selection at three centers. This may be reasonable, but there are no published data to support these criteria, and we have no data to support these criteria.

There is general agreement that patients should have hyperexpanded lungs with a flattened diaphragm. Cooper and associates ${ }^{1}$ have used diaphragm motion less than $3 \mathrm{~cm}$ as a criterion. The data in the present study do not support diaphragmatic excursion as a selection criterion.

Plethysmographic criteria logically should help to select patients for LVRS, and various criteria have been proposed (Table V). Conventional wisdom is 
Table V. Radiologic and pulmonary function selection criteria for LVRS for multiple centers (listed by reference number)

\begin{tabular}{|c|c|c|c|c|c|c|c|c|}
\hline & \multicolumn{8}{|c|}{ Reference number } \\
\hline & 1,2 & 3 & 4 & 5 & 6,7 & 8 & 9,10 & 25 \\
\hline Flat diaph & Yes & - & Yes & Yes & Yes & Yes & Yes & Yes \\
\hline Hetero CT & Yes & Yes & Yes & Yes & Yes & Yes & Yes & Yes \\
\hline $\mathrm{FEV}_{1}$ & $\begin{array}{l}>15 \% \\
<35 \%\end{array}$ & $<40 \%$ & $<30 \%$ & $<35 \%$ & $<35 \%$ & $<35 \%$ & $<35 \%$ & $<40 \%$ \\
\hline TLC & $>125 \%$ & - & - & - & - & - & - & $>120 \%$ \\
\hline RV & $>250 \%$ & - & - & 一 & - & $>200 \%$ & 一 & - \\
\hline $\mathrm{PO}_{2}$ & - & $>40$ & $>40$ & $>40$ & - & $>45$ & $>40$ & - \\
\hline $\mathrm{PCO}_{2}$ & $<55$ & $<60$ & $<55$ & $<50$ & $<50$ & $<55$ & $<55$ & $<50$ \\
\hline DLCO & - & $?$ & 一 & - & $>25 \%$ & - & - & $<50 \%$ \\
\hline
\end{tabular}

Flat diaph, flat diaphragm on chest x-ray film; Hetero CT, heterogeneous pattern of emphysema seen on chest CT scan.

that patients for LVRS should have hyperexpanded lungs; however, the data in this study fail to identify absolute plethysmographic criteria for patient selection. This does not mean, however, that patients with restrictive disease should undergo LVRS, because only one patient in the series had a total lung capacity less than $100 \%$ predicted. This patient's chest $\mathrm{x}$-ray film showed hyperexpanded lungs despite the plethysmographic data. She achieved excellent improvement after the operation.

DLCO has been proposed as a criterion for LVRS. $^{7,25}$ The data in this study again fail to demonstrate an association with clinical outcomes. Gelb showed a lack of association between DLCO and $\mathrm{FEV}_{1}$ when the $\mathrm{FEV}_{1}$ was less than $1 \mathrm{~L}^{13}$ Because the $\mathrm{FEV}_{1}$ is less than $1 \mathrm{~L}$ in essentially all patients for LVRS, the DLCO would not be expected to show any association with the degree of emphysema.

Our data show no significant associations between the preoperative phlethysmographic data and the postoperative change in the $\mathrm{FEV}_{1}$. It was interesting to note that the mean change in the $\mathrm{FEV}_{1}$ was the same $(390 \mathrm{ml})$, irrespective of the preoperative $\mathrm{FEV}_{1}$. We believe that the absolute change in $\mathrm{FEV}_{1}$ should be used for an analysis of this kind because the same absolute change in the $\mathrm{FEV}_{1}(390 \mathrm{ml})$ represents an artificially higher percent change of a low preoperative $\mathrm{FEV}_{1}(78 \%$ of $0.5 \mathrm{~L})$ compared with a higher preoperative $\mathrm{FEV}_{1}(39 \%$ of $1.0 \mathrm{~L})$.

The most significant factor that could be identified was the presence of bilateral upper lobe pattern of emphysema. The Washington University group also found this to be a very important selection factor. ${ }^{1,3}$ Patients with only a mild degree of heterogeneity averaged less improvement than patients with a high degree of heterogeneity (mean increase in $\mathrm{FEV}_{1}<350 \mathrm{ml}$ vs $500 \mathrm{ml}$, respectively). ${ }^{3,25}$

To evaluate the role of emphysema versus small airways disease in chronic obstructive pulmonary disease, Gelb and associates ${ }^{26}$ evaluated 116 consecutively seen outpatients with fixed expiratory airway limitation. Thin-cut high-resolution CT scans demonstrated severe emphysematous change (anatomic destruction graded as $>60$ ) in only $30 \%$. This suggests that LVRS can help only a minority of patients who clinically have emphysema.

Surgical series have reported that $18 \%$ to $24 \%$ of patients screened were deemed candidates for LVRS. $^{2,8}$ In this series, $31 \%$ of the screened patients were accepted because some pulmonologists who regularly refer patients to our center prescreen their patients so that almost all of the patients that they refer are good candidates for the procedure.

In conclusion, in this series of patients undergoing LVRS, the presence of a bilateral upper lobe heterogeneous pattern of emphysema on chest $\mathrm{CT}$ and lung perfusion scan is strongly associated with improved clinical outcome. Patients who require $4 \mathrm{~L}$ of nasal oxygen are not good candidates for LVRS. Although patients over 70 years of age do experience a significant improvement in clinical status, they experienced less improvement than younger patients. After patients have been selected for the presence of a heterogeneous pattern of emphysema, clinical factors and physiology are not significantly associated with clinical outcome. Thus our results do not support further refinement of patient selection criteria for LVRS after patients have been chosen for the presence of a heterogeneous pattern of emphysema. These results do not support the arbitrary patient selection criteria that are reported in the literature. 


\section{REFERENCES}

1. Cooper JD, Trulock EP, Triantafillou AN, Patterson GA Pohl MS, Deloney PA, et al. Bilateral pneumectomy (volume reduction) for chronic obstructive pulmonary disease $\mathbf{J}$ Thorac Cardiovase Surg 1995;109:106-16.

2. Wakabayashi A. Thoracoscopic laser pneumoplasty in the treatment of diffuse bullous emphysema. Ann Thorac Surg 1996;60:936-40.

3. Yusen RD, Lefrak SS, The Wash U Emphysema Group. Evaluation of patients with emphysema for lung volume reduction surgery. Semin Thorac Cardiovasc Surg 1996;1:83-93.

4. Miller JI, Lee RB, Mansour KA. Lung volume reduction surgery: lessons learned. Ann Thorac Surg. In press.

5. Argenziano M, Moazami N, Thomashaw B, et al. Extended indications for volume reduction pneumoplasty in advanced emphysema. Ann Thorac Surg. In press.

6. Keenen RJ, Landreneau RJ, Sciurba FC, et al. Unilateral thoracoscopic surgical approach for diffuse emphysema. J Thorac Cardiovasc Surg 1996;111:308-15.

7. Sciurba FC, Rogers RM, Kennen RJ, et al. Improvement in pulmonary function and elastic recoil after lung reduction surgery for diffuse emphysema. N Engl J Med 1996;334:1095-9.

8. Miller DD, Dowling RD, McConnell JW, Skolnick JL. Effects of lung volume reduction surgery on lung and chest wall mechanics. Ann Thorac Surg. In press.

9. McKenna R, Brenner M, Gelb AF, Mullin M, Singh N, Peters $\mathrm{H}$, et al. A randomized, prospective trial of stapled lung reduction versus laser bullectomy for diffuse emphysema. J Thorac Cardiovasc Surg 1996;111:310-22.

10. McKenna RJ Jr, Brenner M, Gelb AF, Fischel RJ. Should lung volume reduction surgery be unilateral or bilateral? J Thorac Cardiovasc Surg 1996;112:1331-9.

11. Benditt JO, Albert RK. Lung reduction surgery: great expectations and a cautionary note. Chest 1995;107:297-8.

12. Rusch VW. Lung volume reduction surgery: A true advance? J Thorac Cardiovasc Surg 1996;11:293-5.

13. American Thoracic Society. Surveillance for respiratory hazards in the occupational setting. Am Rev Respir Dis 1992;126:952-6.

14. Stewart A, Hays R, Ware J. The MOS short-form general health survey: reliability and validity in a patient population. Med Care 1988;26:724-35.

15. Gelb AF, Schein M, Kuei J, Tashkin DP, Mueller NL, Hogg $\mathrm{JC}$, et al. Limited contribution of emphysema in advanced chronic obstructive pulmonary disease. Am Rev Respir Dis 1993;147:1157-61.

16. DuBois A, Botelho S, Comroe J. A new method for measuring airway resistance in man using a body plethysmograph: values in normal subjects and in patients with respiratory disease. J Clin Invest 1956;35:327-35.

17. American Thoracic Society. Single breath carbon monoxide diffusing capacity (transfer factor): recommendation for a standard technique. Am Rev Respir Dis 1987;136:1307-29.

18. American Thoracic Society. Lung function testing: selection of reference values and interpretative strategies. Am Rev Respir Dis 1991;144:1202-18.

19. Gaensler EA, Smith AA. Attachment for automated single breath diffusing capacity measurement. Chest 1973;63:136-45.

20. Goldman HI, Becklake MR. Respiratory function tests: normal values at median altitudes and the prediction of normal results. Am Rev Tuberc Pulm Dis 1971;103:57-67.

21. Morris JF, Koski A, Johnson LC. Spirometric standards for healthy nonsmoking adults. Am Rev Respir Dis 1971;103:56-67.
22. Pelzer A, Thompson M. Effect of age, sex, stature and smoking habit on human airway conductance. J Appl Physiol 1966:21:469-76.

23. McHorney C, Ware J, Raczek A. The MOS 36-item shortform health survey (SF-36). II. Psychometric and clinical tests of validity in measuring physical and mental health constructs. Med Care 1993;31:247-63.

24. Brown B, Hollander M. Statistics: a biomedical introduction. In: Bradley RA, Hunter J, Kendall DG, Watson GS, editors. Wiley Series in Probability and Mathematical Statistics. New York: John Wiley; 1977.

25. NIH Advisory Guidelines. Emphysema: volume reduction surgery. September 1995.

26. Gelb AF, Hogg JC, Mueller NL, et al. Contribution of emphysema and small airways in COPD. Chest 1996;109:353-9.

\section{Discussion}

Dr. Marvin Pomerantz (Denver, Colo.). I congratulate Dr. McKenna for his leadership role in using bilateral video-assisted thoracic surgery to perform LVRS in appropriate patients with emphysema. Our own experience has been limited to bilateral LVRS using the transsternal approach. We would agree that the most important preoperative factor is the heterogeneous pattern of emphysema with so-called target areas, particularly those lacking perfusion to the upper lung zones. However, we achieved one of our best successes in a patient with $\alpha_{1}$-antitrypsin disease who required $4 \mathrm{~L}$ of supplemental oxygen. She was on our transplant list and could not walk across the room. She had marked emphysematous changes in both lower lobes. We did a right lower lobectomy and resected the basilar segments on the left lower lobe. She now exercises without supplemental oxygen and, in fact, does not use supplemental oxygen at all. We have noted in our patients that the peak oxygen consumption at peak work increased after the operation. This appears to correlate with increases in $\mathrm{FEV}_{1}$ but not with decreases in lung volumes. My first question to Dr. McKenna relates to this finding. Have you noted the same in your series?

Dr. McKenna. The optimal tool to use to evaluate patients after the operation is unknown. As you indicate, the postoperative courses do not always correlate with the $F E V_{1}$. We found patients with dramatic improvements in their clinical abilities, but no changes in the $\mathrm{FEV}_{1}$. The things that we have noticed that correlate the best with outcomes and with what really happens with this operation are the changes in elastic recoil and also the changes in residual volumes. Patients are breathing much farther away from their total lung capacity, and that makes their sense of dyspnea much decreased.

Dr. Pomerantz. My second question relates to the $\mathrm{PaO}_{2}$ and $\mathrm{PaCO}_{2}$. In our patients it seems that the $\mathrm{PCO}_{2}$ decreases more consistently with rest and exercise after the operation than the $\mathrm{PO}_{2}$ increases. Did you have the same experience in this situation?

Dr. McKenna. Yes. The results of the $\mathrm{PCO}_{2}$ dramatically decreased but that did not necessarily correlate with improvement clinically in the patients, and the changes in the room air $\mathrm{PO}_{2}$ have been variable.

Dr. Pomerantz. My last question relates to rehabilitation. Dr. Cooper emphasizes the importance of a 6- to 8 -week pulmonary rehabilitation before the operation. In 
your paper there was no mention of rehabilitation. Do you use rehabilitation? If not, why not?

Dr. McKenna. A significant number of our patients have not had rehabilitation ahead of time. I think that practice is appropriate in properly selected patients. Rehabilitation is a helpful patient selection criteria. It shows that the patients can control their anxiety, can control their depression, and can accomplish the work that they need to accomplish to get benefit from the operation. However, I think the operation can be done without rehabilitation in properly selected patients.

Dr. Pomerantz. Finally, I would caution those investigators who are either just beginning their program to try not to take the outliers that Dr. McKenna presented so well. We may not all have as much expertise as he does. Patients with very low $F E V_{1}$ and those with low $\mathrm{Po}_{2}$ and high $\mathrm{PCO}_{2}$ will often not do well.

Dr. Joseph Bavaria (Philadelphia, Pa.). At the University of Pennsylvania we have done approximately 150 of these operations, and about half of them have been through a mediastinotomy and the other half have been through the video-assisted thoracic approach. I would like for you to comment on the $11 \%$ mortality rate in patients with low $\mathrm{FEV}_{1}$. We have also noted this early in our experience. Recently there have been basically two types of referral patterns: about $75 \%$ of the patients come in directly through the thoracic surgeon's office and the other $25 \%$ actually come in through the lung transplant format. These patients all have an $\mathrm{FEV}_{1}$ of less than $19 \%$. We have found that with patients with an $\mathrm{FEV}_{1}$ of less than or equal to $19 \%$ a bilateral procedure, whether through a mediastinotomy or through a video-assisted thoracic approach, is not appropriate. Instead, we have now gone to a bilateral sequential approach-two unilateral approaches in sequence, and our mortality rate is $0 \%$ in patients with an $\mathrm{FEV}_{1}$ of less than 19 percent. Would you please comment on that? We believe that these patients do not tolerate bilateral manipulation of the lung at the same time very well.

Dr. McKenna. At the 1996 Annual Meeting of The American Association for Thoracic Surgery, we presented a study comparing unilateral and bilateral approaches. We found no difference in our operative morbidity or mortality for the unilateral and bilateral approach in patients who had a severely depressed $\mathrm{PO}_{2}$ or a severely decreased $\mathrm{FEV}_{1}$. The one important factor that we noted, however, was a very significantly increased 1 -year mortality rate for patients who had a very low $\mathrm{FEV}_{1}$ if they had a unilateral operation. My belief is that patients who are severely compromised need to have the best improvement possible, and that is achieved with a bilateral staple operation. We were able to do that without any increased risk compared with a unilateral approach.

Dr. Bavaria. Our approach is also to do a bilateral operation but just to do it sequentially-tactics versus strategics.

My second question concerns oxygen. We found that almost none of our patients who had a low DLCO on their pulmonary function testing were able to dispense with supplemental oxygen. Did you see that in your series as well?

Dr. McKenna. The DLCO correlates very poorly with the presence of emphysema in patients who have an $\mathrm{FEV}_{1}$ less than $1 \mathrm{~L}$. That has been reported by one of the pulmonologists who works with me. The correlation between DLCO and postoperative results was poor, and I did not find that to be predictive.

Dr. Bavaria. Last, do you have any recommendations regarding the ongoing Medicare issues?

Dr. McKenna. Can I have the rest of the day to answer that question? I do not see any way to fight city hall. We need to participate in that trial, get it up and running as fast as possible, and get the data to them so that the overwhelming difference between LVRS and rehabilitation is apparent.

Dr. John Benfield (Sacramento, Calif.). I want to thank Dr. Marvin Pomerantz for his leading role in helping to establish some guidelines with regard to this new procedure. Thoracic surgery and allied specialties are indebted to him for effective work.

There is now an investigational therapeutic protocol that has been advanced by the National Institutes of Health (NIH) in cooperation with the Health Care Finance Agency (HCFA). To my knowledge, this is the very first time that a new approach has been subjected to a prospective study. Within a relatively short period of time it should answer some of the questions that are still pending. We are pushing very hard for a rapid accrual to this protocol so that the unresolved questions will in fact become resolved. Again, to my knowledge this is the first time that HCFA and the NIH have come together, and I think this is an important example of leadership by thoracic surgery and allied medical specialties and cooperation with HCFA and NIH toward the best available patient care.

Dr. Arthur Thomas (San Francisco, Calif.). This is obviously a palliative procedure for a condition that in some patients is self-induced. In the days of cost effectiveness this comes into play. Obviously most if the patients still require supplemental oxygen after the procedure. How much better are they able to function?

You did not mention longevity. Do they really live longer or do they just have a prolonged better experience for the short duration? Second, do you have any mandatory selection criteria, such as not smoking anymore?

Dr. McKenna. Smoking cessation is an absolute requirement to have the operation. Patients must have stopped smoking at least 6 months before the procedure. That is usually not a problem. Most of these patients are in such bad condition that they are no longer able to draw on a cigarette.

You mentioned oxygen. Seventy percent of our patients after a bilateral staple operation are not using supplemental oxygen. Functionally, the patients whose condition improves are dramatically better with this operation. Unfortunately, some note no improvement, and LVRS is not without operative morbidity and mortality. However, in the majority of patients the quality of life is very substantially improved.

I do not have sufficient data to address the question of longevity. The average improvement in the $\mathrm{FEV}_{1}$ in these patients is $400 \mathrm{ml}$. These patients tend to lose about $50 \mathrm{ml}$ per year in their $\mathrm{FEV}_{1}$, so that we would hope that they would get at least 5 years of benefit from the operation. This is certainly a palliative operation. 


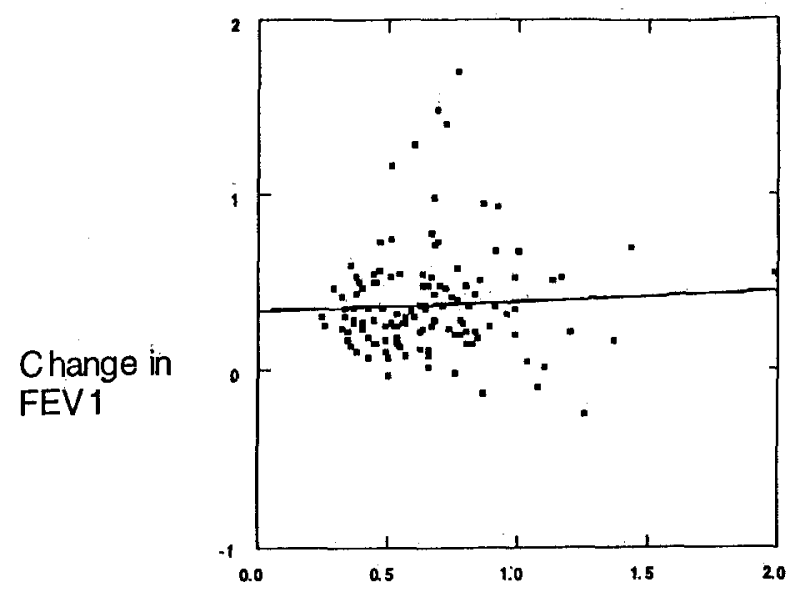

A

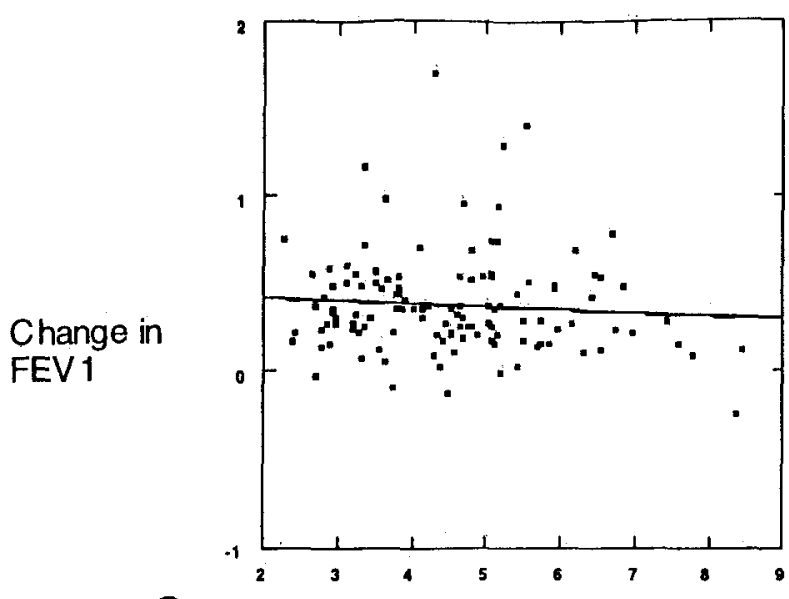

C

RV (Baseline)

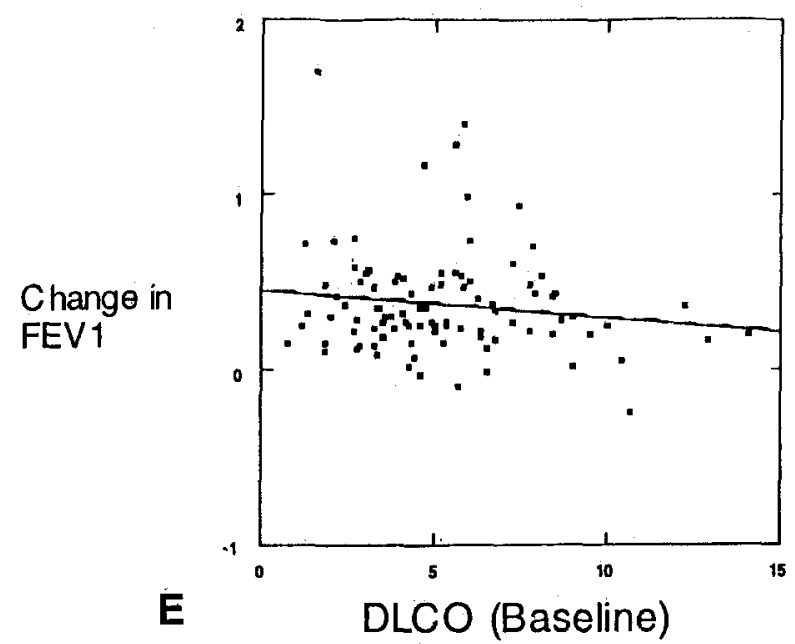

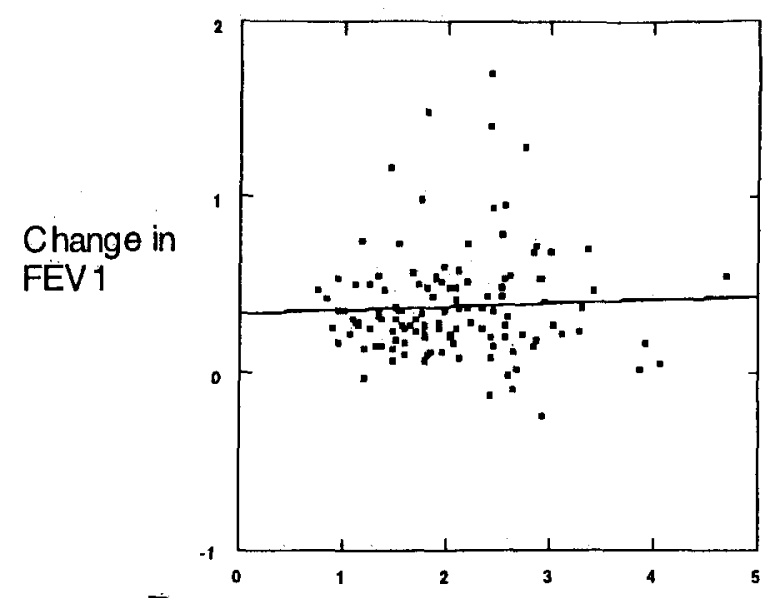

B

FVC (baseline)

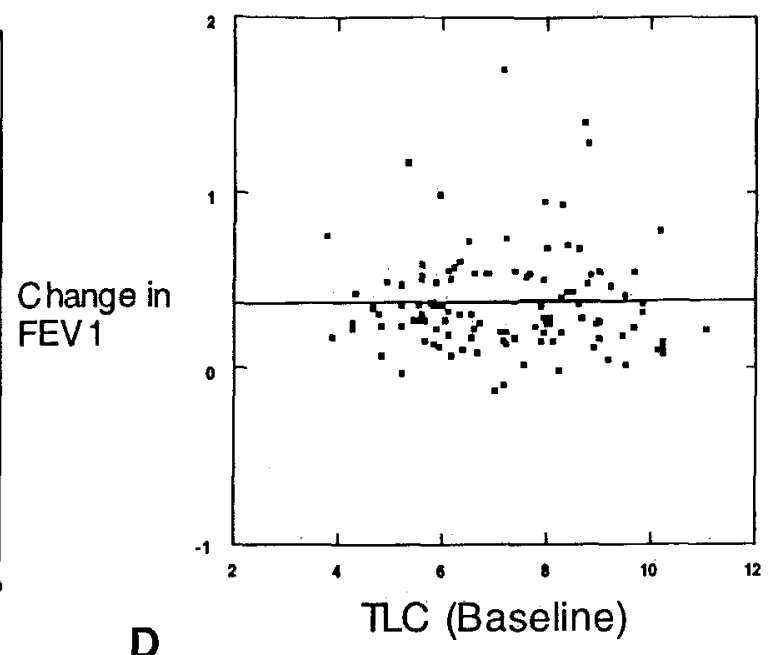

D

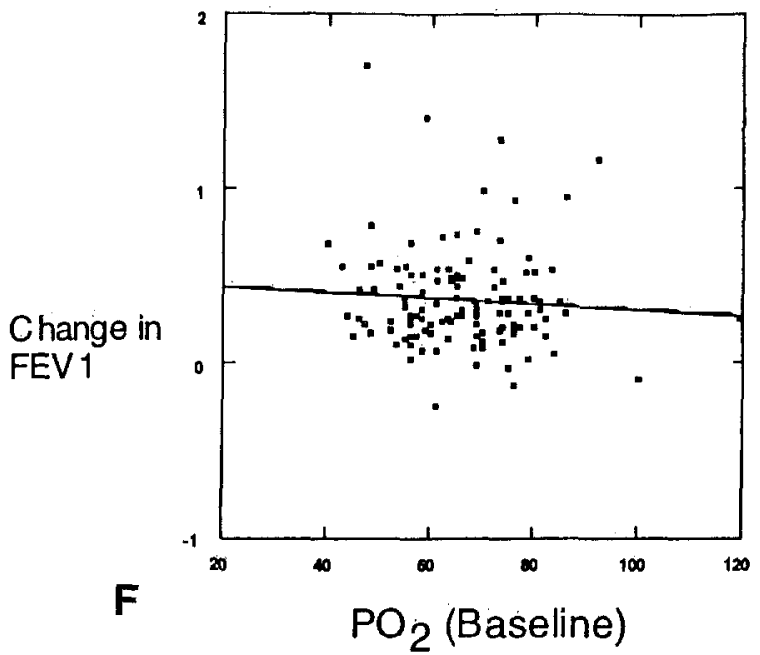

Appendix Fig. 1. Scattergrams comparing the postoperative change in the $\mathrm{FEV}_{1}$ with the preoperative $\mathrm{FEV}_{1}(\mathbf{A})$, preoperative forced vital capacity $(F V C)(\mathbf{B})$, preoperative residual volume $(R V)$ (C), preoperative total lung capacity (TLC) (D), preoperative DLCO (E), and preoperative $\mathrm{PaO}_{2}(\mathbf{F})$. 
Appendix Table I. Relationship between pulmonary function tests, arterial blood gases, and the use of prednisone with the clinical outcome

\begin{tabular}{|c|c|c|c|c|}
\hline & $\triangle F E V_{1}$ & $\% \Delta F E V_{1}$ & $\Delta \%$ Pred & $\Delta$ Dyspnea \\
\hline Variable & Mean $(95 \% \mathrm{Cl})$ & Mean $(95 \%$ CI) & Mean $(95 \%$ CI) & Mean $(95 \% \mathrm{CI})$ \\
\hline \multicolumn{5}{|l|}{$\mathrm{FEV}_{1}$} \\
\hline$<0.5 \mathrm{~L}$ & $0.33(0.28,0.39)$ & $86.90(73.15,100.68)$ & $14.30(12.10,16.50)$ & $1.71(1.36,2.05)$ \\
\hline $0.5-0.75 \mathrm{~L}$ & $0.41(0.32,0.50)$ & $66.37(51.89,80.85)$ & $15.76(12.54,19.00)$ & $1.70(1.39,2.00)$ \\
\hline$>0.75 \mathrm{~L}$ & $0.38(0.29,0.49)$ & $41.94(28.49,55.39)$ & $13.95(9.92,17.98)$ & $1.63(1.16,2.09)$ \\
\hline Significance* & $p=0.49$ & $p=0.0004$ & $p=0.70$ & $p=0.95$ \\
\hline \multicolumn{5}{|l|}{$\mathrm{RV}$} \\
\hline$\leq 150 \%$ & $0.39(0.26,0.52)$ & $70.90(42.60,99.20)$ & $15.71(10.44,20.98)$ & $2.21(1.77,2.65)$ \\
\hline $151-180 \%$ & $0.42(0.29,0.56)$ & $70.87(51.27,90.47)$ & $16.84(12.28,21.40)$ & $1.65(1.25,2.06)$ \\
\hline $181-205 \%$ & $0.32(0.24,0.40)$ & $62.20(45.50,78.91)$ & $13.31(9.93,16.69)$ & $1.86(1.44,2.28)$ \\
\hline $206-230 \%$ & $0.33(0.24,0.42)$ & $46.09(34.48,57.70)$ & $12.84(9.35,16.33)$ & $1.78(1.15,2.40)$ \\
\hline$>230 \%$ & $0.41(0.28,0.54)$ & $74.03(53.08,94.99)$ & $14.78(10.22,19.34)$ & $1.39(0.99,1.79)$ \\
\hline Significance* & $p=0.66$ & $p=0.24$ & $p=0.67$ & $p=0.27$ \\
\hline \multicolumn{5}{|l|}{ TLC } \\
\hline$\leq 100 \%$ & $0.35(0.21,0.49)$ & $71.84(41.78,101.91)$ & $15.19(9.41,20.96)$ & $2.05(1.36,2.73)$ \\
\hline $101-110 \%$ & $0.46(0.27,0.65)$ & $88.43(60.61,116.26)$ & $17.25(10.87,23.62)$ & $1.79(1.24,2.34)$ \\
\hline $111-120 \%$ & $0.35(0.24,0.46)$ & $46.86(33.62,60.11)$ & $13.12(9.32,17.04)$ & $1.33(0.78,1.88)$ \\
\hline $121-130 \%$ & $0.33(0.23,0.42)$ & $55.18(37.96,72.40)$ & $13.49(9.40,17.59)$ & $1.87(1.44,2.29)$ \\
\hline $131-140 \%$ & $0.43(0.31,0.54)$ & $69.09(51.47,86.72)$ & $16.42(12.42,20.42)$ & $1.78(1.24,2.32)$ \\
\hline$>140 \%$ & $0.35(0.22,0.49)$ & $57.44(34.43,80.44)$ & $13.13(8.25,18.01)$ & $1.53(1.02,2.04)$ \\
\hline Significance* & $p=0.68$ & $p=0.13$ & $p=0.74$ & $p=0.53$ \\
\hline \multicolumn{5}{|l|}{$\mathrm{PaO}_{2}$} \\
\hline$\leq 55 \mathrm{~mm} \mathrm{Hg}$ & $0.42(0.31,0.58)$ & $78.23(59.51,96.96)$ & $16.91(12.68,21.14)$ & $1.63(1.10,2.15)$ \\
\hline $55-60 \mathrm{~mm} \mathrm{Hg}$ & $0.32(0.19,0.45)$ & $58.35(38.25,78.46)$ & $12.43(7.85,17.00)$ & $1.29(0.80,1.79)$ \\
\hline $61-65 \mathrm{~mm} \mathrm{Hg}$ & $0.38(0.28,0.48)$ & $71.09(51.38,90.80)$ & $14.81(10.74,18.87)$ & $1.83(1.35,2.41)$ \\
\hline $66-75 \mathrm{~mm} \mathrm{Hg}$ & $0.35(0.26,0.44)$ & $55.50(39.75,79.17)$ & $14.23(10.45,18.01)$ & $1.76(1.40,2.12)$ \\
\hline$>75 \mathrm{~mm} \mathrm{Hg}$ & $0.35(0.23,0.47)$ & $55.87(35.23,76.50)$ & $13.73(9.59,17.88)$ & $1.75(1.26,2.24)$ \\
\hline Significance* & $p=0.67$ & $p=0.35$ & $p=0.71$ & $p=0.56$ \\
\hline \multicolumn{5}{|l|}{$\mathrm{PaCO}_{2}$} \\
\hline$\leq 35 \mathrm{~mm} \mathrm{Hg}$ & $0.38(0.24,0.53)$ & $47.23(28.15,66.32)$ & $14.64(8.46,20.82)$ & $1.32(0.86,1.78)$ \\
\hline $36-40 \mathrm{~mm} \mathrm{Hg}$ & $0.41(0.33,0.49)$ & $64.26(50.71,77.80)$ & $15.55(12.51,18.59)$ & $1.71(1.30,2.12)$ \\
\hline $41-45 \mathrm{~mm} \mathrm{Hg}$ & $0.38(0.28,0.48)$ & $66.82(49.90,83.74)$ & $14.86(11.22,18.49)$ & $1.85(1.44,2.26)$ \\
\hline $46-55 \mathrm{~mm} \mathrm{Hg}$ & $0.28(0.19,0.38)$ & $60.39(41.68,79.09)$ & $11.99(8.20,15.70)$ & $1.66(1.26,2.06)$ \\
\hline$>55 \mathrm{~mm} \mathrm{Hg}$ & $0.33(0.12,0.54)$ & $71.16(29.54,112.77)$ & $13.48(6.92,20.05)$ & $1.38(0.64,2.11)$ \\
\hline Significance* & $p=0.56$ & $p=0.70$ & $p=0.79$ & $p=0.62$ \\
\hline \multicolumn{5}{|l|}{ Pred. } \\
\hline 0 & $0.36(0.30,0.43)$ & $61.32(49.89,72.76)$ & $14.21(11.90,16.52)$ & $1.60(1.28,1.91)$ \\
\hline $1-5 \mathrm{mg}$ & $0.35(0.23,0.48)$ & $61.02(43.48,78.55)$ & $14.64(9.63,19.65)$ & $1.31(0.85,1.78)$ \\
\hline $6-10 \mathrm{mg}$ & $0.48(0.32,0.65)$ & $80.67(56.67,104.67)$ & $18.32(12.81,23.83)$ & $2.14(1.74,2.53)$ \\
\hline$>10 \mathrm{mg}$ & $0.34(0.16,0.51)$ & $61.52(27.39,95.65)$ & $12.67(6.98,18.36)$ & $1.06(0.35,1.76)$ \\
\hline Significance* & $p=0.34$ & $p=0.34$ & $p=0.34$ & $p=0.03$ \\
\hline
\end{tabular}

Pred., Preoperative dose of prednisone; $\triangle F E V_{1}$, change from baseline $\mathrm{FEV}_{1}$ in liters; $\% \Delta F E V_{1}$, percent change from baseline FEV in liters; $\triangle \%$ Pred, change from baseline percent predicted $\mathrm{FEV}_{\mathbf{1}} ; \Delta$ Dyspnea, change in dyspnea score. 